\title{
Alternating Copolymerization of Methyl $\alpha$-Phenylacrylate and Various Methacrylates
}

\author{
Heimei Yuki, Koji Ohta, Koichi Hatada, and Hiroyuki IshiKawa \\ Department of Chemistry, Faculty of Engineering Science, \\ Osaka University, Toyonaka, Osaka 560, Japan.
}

(Received August 17, 1978)

\begin{abstract}
Methyl $\alpha$-phenylacrylate (MPhA) was copolymerized with methacrylates which have ester groups of various sizes, such as benzyl, $\alpha$-methylbenzyl, diphenylmethyl, $\alpha, \alpha$-dimethylbenzyl, 1,1-diphenylethyl, and trityl groups. The copolymerization was carried out with butyllithium in toluene and tetrahydrofuran at various temperatures with an initial monomer ratio of $1: 1$. In both solvents the copolymers with highly alternating structure were obtained at 0 and $30^{\circ} \mathrm{C}$, except for the case in which 1,1-diphenylethyl methacrylate was used as the comonomer in toluene. In general the copolymers were atactic. However, the coisotacticity of the alternating copolymers increased with increasing bulkiness of methacrylate and reached about $60 \%$ in the copolymer of MPhA and trityl methacrylate regardless of the polymerization medium. At -40 and $-78^{\circ} \mathrm{C} \mathrm{MPhA} \mathrm{was} \mathrm{more} \mathrm{reactive} \mathrm{than} \mathrm{the}$ methacrylates. The optical activity of the copolymer of $\mathrm{MPhA}$ and $(S)$ - $\alpha$-methylbenzyl methacrylate was lower than the calculated value, and the difference increased as the content of the alternating sequence increased. The circular dichroism spectrum of the optically active copolymer was also measured.

KEY WORDS Alternating Copolymerization / Methyl $\alpha$-Phenylacrylate / Methacrylate / Butyllithium / ${ }^{1} \mathrm{H}-\mathrm{NMR}$ Spectrum / Trityl Methacrylate / Coisotacticity / $(S)-\alpha$-Methylbenzyl Methacrylate / Optical Activity / Circular Dichroism Spectrum /
\end{abstract}

We have previously investigated the anionic copolymerization of methyl $\alpha$-phenylacrylate (MPhA) and methyl methacrylate (MMA) with butyllithium $(\mathrm{BuLi})$ in toluene and tetrahydrofuran (THF) at various temperatures. The polymerization of MPhA was predominant at low temperatures, but the alternating copolymer of the two monomers was obtained above $30^{\circ} \mathrm{C}$ in toluene and above $0^{\circ} \mathrm{C}$ in $\mathrm{THF}^{1,2}$ The cotacticity of the copolymer was almost random.

In this work the copolymerization of MPhA with various methacrylates was carried out with BuLi in toluene and in THF at 30,0,-40, and $-78^{\circ} \mathrm{C}$. The methacrylates were of benzyl, $(S)$ and (RS)- $\alpha$-methylbenzyl, diphenylmethyl, $\alpha, \alpha$ dimethylbenzyl, 1,1-diphenylethyl, trityl, and deuterated methyl. The reactivity of the monomers in the copolymerization and the microstructure of the alternating copolymers were studied. The chiroptical property of the copolymer of MPhA and $(S)-\alpha$-methylbenzyl methacrylate [(S)-MBMA] was also investigated.

\section{EXPERIMENTAL}

\section{Materials}

MPhA was prepared from methyl phenylacetate, dimethyl oxalate, and sodium methoxide as described in a previous paper. ${ }^{3}$ bp $59.5-60.5^{\circ} \mathrm{C}$ (2 mmHg).

MMA with a deuterated methoxyl group (MMA$d_{3}$ ) was prepared from methacryloyl chloride and methanol- $d_{4}$.

Commercial benzyl methacrylate (BzMA) was purified by distillation and redistilled over $\mathrm{CaH}_{2}$ before use. bp $86^{\circ} \mathrm{C}(1 \mathrm{mmHg})$.

$(S)$-MBMA was prepared from methacryloyl chloride and $(S)-\alpha$-methylbenzyl alcohol. ${ }^{4}$ bp 
$50.5^{\circ} \mathrm{C} \quad(0.15 \mathrm{mmHg}), \quad[\alpha]_{589}^{20} \quad-5.30 \mathrm{deg} \mathrm{cm}^{2} / \mathrm{g}^{*}$ (neat, $1=2 \mathrm{~cm}$ ).

$(R S)$-MBMA, diphenylmethyl methacrylate (DPMMA, mp $80-82^{\circ} \mathrm{C}$ ), ${ }^{5}$ and $\alpha, \alpha$-dimethylbenzyl methacrylate [DMBMA, bp $70^{\circ} \mathrm{C}(0.4$ $\mathrm{mmHg})]^{6}$ were prepared from the corresponding alcohols and methacryloyl chloride in the presence of triethylamine in diethyl ether.

1,1-Diphenylethyl methacrylate (DPEMA, mp $\left.34-35^{\circ} \mathrm{C}\right)^{7}$ and trityl methacrylate (TrMA, mp $\left.103-103.5^{\circ} \mathrm{C}\right)^{8}$ were prepared from the corresponding chlorides and silver methacrylate in diethyl ether.

Toluene was purified in the usual manner and stored over sodium. Before use it was mixed with a small amount of BuLi in toluene and distilled under high vacuum.

THF was refluxed and distilled over $\mathrm{CaH}_{2}$. It was redistilled over $\mathrm{LiAlH}_{4}$ under high vacuum just before use.

$\mathrm{BuLi}$ was prepared from metallic lithium and butyl chloride in heptane or in toluene under argon. $^{9}$

Nitrogen was purified by passing it through a column packed with type-4A molecular sieves cooled at $-78^{\circ} \mathrm{C}$.

\section{Copolymerization}

A glass ampoule was flame-dried while being evacuated and was filled with dry nitrogen. The solid monomer was first placed in the ampoule. It was again evacuated and flushed with nitrogen, and this procedure was repeated three times. The liquid monomer and the solvent were added by hypodermic syringes under nitrogen. The catalyst was then added with a syringe at a given temperature. After a desired reaction time, the polymerization was terminated by a small amount of methanol and the polymer was precipitated by pouring the reaction mixture into a large amount of methanol. The polymer was collected by filtration, washed several times with methanol, and dried in vacuo at $60^{\circ} \mathrm{C}$.

\section{Conversion of Poly(MPhA-co-methacrylate) to Poly (MPhA-co-MMA) \\ The MBMA and DPMMA units in the copoly-}

* In this paper, the CGS unit system is used to represent specific rotation and specific ellipticity. This gives values 10 times lower than the conventional specific quantity $\left(\mathrm{deg} \mathrm{cm}^{3} / \mathrm{g} \mathrm{dm}\right)$. mers were quantitatively converted to the methacrylic acid (MAA) units by the reaction with dry hydrogen bromide in toluene. ${ }^{4}$ The ester groups of the DMBMA, DPEMA, and TrMA units were selectively hydrolyzed by refluxing the copolymers in methanol containing a small amount of hydrochloric acid. ${ }^{6-8}$ The poly(MPhA-co-MAA)s thus obtained were methylated with diazomethane to give poly(MPhA-co-MMA)s.

\section{Measurements}

${ }^{1} \mathrm{H}-\mathrm{NMR}$ spectra were taken on a JNM-MH-100 spectrometer at $100 \mathrm{MHz}$. The spectra of copolymers were measured in $\mathrm{CCl}_{4}$ at $60^{\circ} \mathrm{C}$ using tetramethylsilane as an internal reference or in nitrobenzene- $d_{5}$ at $135^{\circ} \mathrm{C}$ using hexamethyldisiloxane as an internal standard.

Solution viscosities were determined in toluene by an Ostwald viscometer at $30.0 \pm 0.02^{\circ} \mathrm{C}$. The concentration of the polymer solution was $5 \mathrm{mg} / \mathrm{ml}$.

The optical rotation at $589 \mathrm{~nm}$ was measured on a Yanagimoto OR-10 polarimeter in toluene at $20^{\circ} \mathrm{C}$. The concentration of the solution was $0.02 \mathrm{~g} / \mathrm{m} l$ and a cell with a pathlength of $5 \mathrm{~cm}$ was used. The precision of readings was \pm 0.003 deg.

The circular dichroism (CD) spectrum was taken for a THF solution (about $1 \mathrm{mg} / \mathrm{ml}$ ) using a JASCO J-40 spectropolarimeter equipped with a computerizing data processor. The spectra were obtained as an average of 16 separate scans between 200 and $260 \mathrm{~nm}$ using a cell with a pathlength of $0.1 \mathrm{~mm}$ and as an average of 8 scans between 240 and $300 \mathrm{~nm}$ using a $1 \mathrm{~cm}$ cell.

\section{RESULTS}

The copolymerization of MPhA $\left(\mathrm{M}_{2}\right)$ and methacrylates $\left(M_{1}\right)$ were carried out with equimolar amounts of comonomers. The copolymer composition was determined from the ${ }^{1} \mathrm{H}-\mathrm{NMR}$ spectrum of the original copolymer when $M_{1}$ was MMA, MMA- $d_{3}$, BzMA, MBMA, or DPMMA, and from the spectrum of the derived poly(MPhAco-MMA) when DMBMA, DPEMA, or TrMA was used as $\mathrm{M}_{1}$. The ${ }^{1} \mathrm{H}$-NMR spectra of the four copolymers are shown in Figure 1: (A) poly(MPhA-co-MMA), (B) poly(MPhA-co-MMA- $d_{3}$ ), (C) poly(MPhA-co-MMA) which was derived 


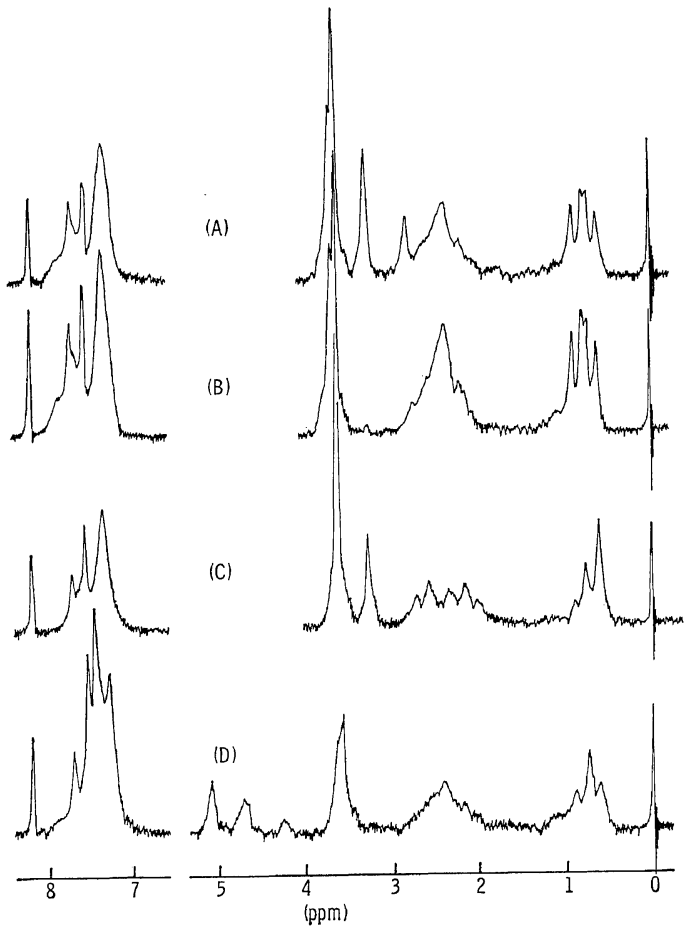

Figure 1. ${ }^{1} \mathrm{H}-\mathrm{NMR}$ spectra of (A) poly(MPhAco-MMA), (B) poly(MPhA-co-MMA- $\left.d_{3}\right)$, (C) poly(MPhA-co-MMA) derived from poly(MPhA-coTrMA), and (D) poly(MPhA-co-BzMA), obtained with $\mathrm{BuLi}$ in toluene at $30^{\circ} \mathrm{C}: \mathrm{C}_{8} \mathrm{D}_{5} \mathrm{NO}_{2}, 100 \mathrm{MHz}$; $135^{\circ} \mathrm{C}$, HMDS.

from poly(MPhA-co-TrMA), and (D) poly(MPhAco-BzMA). The copolymers $\mathrm{A}, \mathrm{B}, \mathrm{D}$, and the poly(MPhA-co-TrMA) described above were obtained in toluene at $30^{\circ} \mathrm{C}$.

It is known that the copolymer of MPhA and MMA prepared above $30^{\circ} \mathrm{C}$ has a highly alternating structure composed of these two monomers. ${ }^{1,2}$ In spectrum $\mathrm{A}$, the $\alpha$-methyl proton resonance of the MMA unit appears at higher magnetic field $(0.63-0.90 \mathrm{ppm})$ than that of PMMA (1.14-1.36 ppm) due to the shielding effect of benzene rings in the MPhA units on both sides of the MMA unit. Therefore, the content of the alternating triad centered by the MMA unit, $\mathrm{m}_{2} \mathrm{~m}_{1} \mathrm{~m}_{2}$, can be determined from the intensities of these $\alpha$-methyl proton signals. The peak separation of the $\alpha$ methyl and methoxyl methyl resonances in spectrum $\mathrm{A}$ has been also assigned as follows: $:^{1,2}$ the three peaks of $\alpha$-methyl protons at $0.63,0.76$, and $0.90 \mathrm{ppm}$ are due to the coisotactic (I), coheterotactic $(H)$, and cosyndiotactic $(S)$ triads centered by the MMA unit, respectively, while the peaks of methoxyl methyl protons at $2.85,3.28$, and $3.63 \mathrm{ppm}$ are attributable to $S, H$, and $I$ with decreasing magnetic field. The peak at $3.63 \mathrm{ppm}$ overlaps with the methoxyl signal of the MPhA unit.

The poly(MPhA-co-MMA- $d_{3}$ ) has also a highly alternating structure and was prepared in order to check the assignment of the methoxyl methyl signals. In spectrum (B) of this copolymer, the three peaks due to methoxyl protons of the MMA unit disappear, although the methoxyl methyl proton signal of the $\mathrm{MPhA}$ unit remains at 3.63 ppm. The intensity ratio between the signals of methoxyl methyl protons and methylene protons decreased from 1.54 in spectrum $A$ to 0.80 in spectrum $B$.

The ${ }^{1} \mathrm{H}-\mathrm{NMR}$ spectra of the copolymers other than poly(MPhA-co-MMA) and poly(MPhA-coBzMA) showed no peak separation in their $\alpha$ methyl proton resonances. Therefore, the content of the alternating sequence and the cotacticity in these copolymers were determined from the spectrum of the derived poly(MPhA-co-MMA). Spectrum $C$ shows that the sample polymer, and accordingly its original copolymer, poly( $\mathrm{MPhA}-$ co-TrMA), is highly alternating. The stronger intensities of the peaks at 0.63 and $3.63 \mathrm{ppm}$ accompanied with the weaker ones of the peaks at 0.90 and $2.85 \mathrm{ppm}$ indicate a high content of coisotacticity in this copolymer. From the relative intensities of the peaks in the region of $\alpha$ methyl signals, the $I, H$, and $S$ contents of the polymer, and consequently of the poly(MPhAco-TrMA), were determined to be 60,33 , and $7 \%$, respectively. In the alternating copolymer of MPhA and MMA, the two methylene protons are not equivalent to each other, since some of the substitutents attached to the neighboring carbon atoms on both sides are different. Thus the signals might be a quartet regardless of the situation of the methylene group either in meso or in racemic dyad. Spectrum C clearly shows an AB quartet at $2.01,2.17,2.57$, and $2.73 \mathrm{ppm}$ in the region of methylene proton resonance. However, a peak is also observed at $2.36 \mathrm{ppm}$, which is predominant in spectra $\mathbf{A}$ and $\mathbf{B}$, indicating that the quartet is assignable to the meso methylene protons, while 
the resonance of the racemic protons appears as a singlet rather than a quartet.

In spectrum $D$ the peak separation due to cotactic triads which is observed in the $\alpha$-methyl resonance is similar to that found in the case of the alternating poly(MPhA-co-MMA). Thus the cotacticity of the alternating sequence could be determined from these signals. The benzyl methylene resonance also split into three peaks (4.30, 4.76, and $5.13 \mathrm{ppm})$. These peaks may be assigned to $S, H$, and $I$ with decreasing magnetic field. However, the $I$ content obtained from these signals was higher than that obtained from the $\alpha$-methyl resonance, because this copolymer contained the sequence connecting two or more BzMA units in addition to the alternating sequence, and the peak due to $I$ overlaps with the benzyl methylene signals in the former sequence. A similar phenomenon was found for the methyne proton resonance of the $\alpha$-methylbenzyl group in poly(MPhA-co-MBMA).

The results of the copolymerization in toluene at 0 and $30^{\circ} \mathrm{C}$ are shown in Table I. The content of $\mathrm{m}_{2} \mathrm{~m}_{1} \mathrm{~m}_{2}$ triad is represented as the $\mathrm{mol} \%$ in the triad sequences centered by the methacrylate unit $\left(\mathrm{m}_{2} \mathrm{~m}_{1} \mathrm{~m}_{2}, \mathrm{~m}_{1} \mathrm{~m}_{1} \mathrm{~m}_{2}, \mathrm{~m}_{2} \mathrm{~m}_{1} \mathrm{~m}_{1}\right.$, and $\left.\mathrm{m}_{1} \mathrm{~m}_{1} \mathrm{~m}_{1}\right)$. This can be a measure of the content of alternating sequence, when the copolymer is composed of a 1:1 molar ratio of the $\mathbf{M}_{1}$ and $\mathbf{M}_{2}$ units. The copolymers had highly alternating structure in all cases, except for the case in which DPEMA was used as a comonomer. The coisotacticity of triads centered by the methacrylate unit increased with an increase in the bulkiness of the ester group in methacrylate. It changed from $25 \%$ in poly(MPhA-co-MMA) to about $60 \%$ in the copolymer of MPhA and TrMA. In the copolymerization of MPhA and DPEMA the latter monomer was preferentially incorporated into the polymer, yielding a copolymer with a low content of the alternating sequence. Therefore, the cotacticity of poly(MPhA-co-DPEMA) was not determined.

The copolymerization of MPhA with each of the methacrylates was also carried out in THF under conditions similar to those in toluene. As shown in Table II, highly alternating copolymers were obtained in all cases investigated. The cotacticity in each alternating copolymer was very close to that in the corresponding copolymer obtained in toluene.

The results of the copolymerizations at -40 and $-78^{\circ} \mathrm{C}$ are shown in Table III. In general, the reactivity of $\mathrm{MPhA}$ overcomes the reactivity of the methacrylates at low temperatures, especially in toluene. Only a homopolymer of MPhA was obtained in the copolymerizations with bulky methacrylates in this solvent. The reactivity of methacrylates as well as the overall rate of the polymerization were high in THF, in comparison with those in toluene. In THF, $(R S)$-MBMA

Table I. Anionic copolymerization of MPhA $\left(M_{2}\right)$ and methacrylate $\left(M_{1}\right)$ with $\mathrm{BuLi}$ in toluene at 0 and $30^{\circ} \mathrm{C}^{\mathrm{a}}$

\begin{tabular}{|c|c|c|c|c|c|c|c|c|c|}
\hline \multirow{2}{*}{ PMA } & \multirow{2}{*}{$\underset{{ }^{\circ} \mathrm{C}}{\mathrm{Temp}}$} & \multirow{2}{*}{$\underset{h}{\text { Time, }}$} & \multirow{2}{*}{$\begin{array}{l}\text { Yield, } \\
\text { wt \% }\end{array}$} & \multirow{2}{*}{$\underset{\mathrm{mol} / \mathrm{mol}}{\mathrm{m}_{1} / \mathrm{m}_{1}+\mathrm{m}_{2}{ }^{\mathrm{b}}}$} & \multirow{2}{*}{$\begin{array}{l}\mathrm{m}_{2} \mathrm{~m}_{1} \mathrm{~m}_{2}{ }^{\mathrm{c}} \\
\mathrm{mol} \%\end{array}$} & \multicolumn{3}{|c|}{ Cotacticity, \% } & \multirow{2}{*}{$\begin{array}{r}\eta_{\mathrm{sp}} / c \\
\mathrm{~d} l / \mathrm{g}\end{array}$} \\
\hline & & & & & & $I$ & $H$ & $S$ & \\
\hline $\mathrm{MMA}^{\mathrm{d}}$ & 30 & 96 & 59 & 0.53 & 100 & 25 & 50 & 25 & 0.05 \\
\hline MMA- $d_{3}$ & 30 & 48 & 42 & 0.51 & 92 & 26 & 48 & 26 & 0.05 \\
\hline BzMA & 30 & 48 & 29 & 0.48 & 91 & 27 & 49 & 24 & 0.05 \\
\hline$(R S)$-MBMA & 30 & 24 & 83 & 0.50 & 89 & 30 & 48 & 22 & 0.08 \\
\hline DPMMA & 30 & 48 & 66 & 0.55 & 87 & 30 & 45 & 25 & 0.05 \\
\hline DMBMA & 0 & 48 & 50 & 0.52 & 94 & 35 & 47 & 18 & 0.05 \\
\hline DMBMA & 30 & 48 & 50 & 0.54 & 89 & 40 & 45 & 15 & 0.06 \\
\hline DPEMA & 0 & 24 & 84 & 0.62 & 72 & - & - & - & 0.04 \\
\hline DPEMA & 30 & 24 & 80 & 0.69 & 54 & - & - & - & 0.05 \\
\hline TrMA & 0 & 48 & 70 & 0.44 & 96 & 62 & 32 & 6 & 0.06 \\
\hline TrMA & 30 & 48 & 47 & 0.49 & 95 & 60 & 33 & 7 & 0.06 \\
\hline
\end{tabular}

a $\mathrm{M}_{1}, 6.8 \mathrm{mmol} ; \mathrm{M}_{2}, 6.8 \mathrm{mmol}$; BuLi, $0.68 \mathrm{mmol}$; toluene, $8 \mathrm{ml}$.

b Copolymer composition.

c $\mathrm{m}_{2} \mathrm{~m}_{1} \mathrm{~m}_{2} /\left(\mathrm{m}_{2} \mathrm{~m}_{1} \mathrm{~m}_{2}+\mathrm{m}_{2} \mathrm{~m}_{1} \mathrm{~m}_{1}+\mathrm{m}_{1} \mathrm{~m}_{1} \mathrm{~m}_{2}+\mathrm{m}_{1} \mathrm{~m}_{1} \mathrm{~m}_{1}\right)$.

d Reference 2 . 
Copolymn. of $\mathrm{Me} \alpha-\mathrm{Ph}$-acrylate and Methacrylates

Table II. Anionic copolymerization of $\mathrm{MPhA}\left(\mathrm{M}_{2}\right)$ and methacrylate $\left(\mathrm{M}_{1}\right)$ with $\mathrm{BuLi}$ in THF at 0 and $30^{\circ} \mathrm{C}^{\mathrm{a}}$

\begin{tabular}{|c|c|c|c|c|c|c|c|c|c|}
\hline \multirow{2}{*}{ RMA } & \multirow{2}{*}{$\underset{{ }^{\circ} \mathrm{C}}{\text { Temp, }}$} & \multirow{2}{*}{$\underset{\mathrm{h}}{\mathrm{Time}}$} & \multirow{2}{*}{$\begin{array}{l}\text { Yield, } \\
\text { wt \% }\end{array}$} & \multirow{2}{*}{$\underset{\mathrm{mol} / \mathrm{mol}}{\mathrm{m}_{1} / \mathrm{m}_{1}+\mathrm{m}_{2}{ }^{\mathrm{b}}}$} & \multirow{2}{*}{$\begin{array}{c}\mathrm{m}_{2} \mathrm{~m}_{1} \mathrm{~m}_{2}{ }^{\mathrm{c}} \\
\mathrm{mol}_{\mathrm{o}}\end{array}$} & \multicolumn{3}{|c|}{ Cotacticity, \% } & \multirow{2}{*}{$\begin{array}{l}\eta_{\mathrm{sp}} / c \\
\mathrm{~d} l / \mathrm{g}\end{array}$} \\
\hline & & & & & & $I$ & $H$ & $S$ & \\
\hline $\mathrm{MMA}^{\mathrm{d}}$ & 30 & 48 & 26 & 0.52 & 100 & 25 & 50 & 25 & 0.06 \\
\hline BzMA & 30 & 24 & 13 & 0.52 & 90 & 29 & 48 & 23 & 0.04 \\
\hline$(R S)$-MBMA & 30 & 24 & 85 & 0.48 & 90 & 29 & 48 & 23 & 0.10 \\
\hline DPMMA & 30 & 24 & 83 & 0.55 & 85 & 27 & 48 & 25 & 0.06 \\
\hline DMBMA & 0 & 24 & 78 & 0.53 & 93 & 39 & 45 & 16 & 0.08 \\
\hline DMBMA & 30 & 24 & 56 & 0.48 & 91 & 39 & 44 & 17 & 0.10 \\
\hline DPEMA & 0 & 24 & 93 & 0.55 & 80 & 39 & 42 & 19 & 0.05 \\
\hline TrMA & 0 & 24 & 90 & 0.51 & 85 & 60 & 32 & 8 & 0.06 \\
\hline
\end{tabular}

a $\mathrm{M}_{1}, 6.8 \mathrm{mmol} ; \mathrm{M}_{2}, 6.8 \mathrm{mmol}$; BuLi, $0.68 \mathrm{mmol}$; THF, $8 \mathrm{ml}$.

b Copolymer composition.

c $\mathrm{m}_{2} \mathrm{~m}_{1} \mathrm{~m}_{2} /\left(\mathrm{m}_{2} \mathrm{~m}_{1} \mathrm{~m}_{2}+\mathrm{m}_{2} \mathrm{~m}_{1} \mathrm{~m}_{1}+\mathrm{m}_{1} \mathrm{~m}_{1} \mathrm{~m}_{2}+\mathrm{m}_{1} \mathrm{~m}_{1} \mathrm{~m}_{1}\right)$.

d Reference 2.

Table III. Anionic copolymerization of $\operatorname{MPhA}\left(\mathrm{M}_{2}\right)$ and methacrylate $\left(\mathrm{M}_{1}\right)$ with BuLi in toluene and in THF at low temperatures ${ }^{2}$

\begin{tabular}{|c|c|c|c|c|c|c|c|}
\hline \multirow{2}{*}{ RMA } & \multirow{2}{*}{$\begin{array}{c}\text { Temp } \\
{ }^{\circ} \mathrm{C}\end{array}$} & \multicolumn{3}{|c|}{ in Toluene } & \multicolumn{3}{|c|}{ in $\mathrm{THF}$} \\
\hline & & Time, & $\begin{array}{l}\text { Yield, } \\
\text { wt \% }\end{array}$ & $\begin{array}{c}\mathrm{m}_{1} / \mathrm{m}_{1}+\mathrm{m}_{2} \\
\mathrm{~mol} / \mathrm{mol}\end{array}$ & $\underset{h}{\text { Time, }}$ & $\begin{array}{l}\text { Yield, } \\
\text { wt \% }\end{array}$ & $\underset{1}{\mathrm{~m}_{1} / \mathrm{m}_{1}+\mathrm{m}_{2},{ }^{\mathrm{b}}}$ \\
\hline $\mathrm{MMA}^{\mathrm{c}}$ & -78 & 24 & 15 & 0.03 & 48 & 67 & 0.58 \\
\hline$(R S)$-MBMA & -78 & 24 & 9 & 0.02 & 24 & 91 & $0.52^{\mathrm{d}}$ \\
\hline DMBMA & -78 & 72 & 9 & 0.00 & 24 & 36 & 0.01 \\
\hline TrMA & -78 & 48 & 7 & 0.00 & 24 & 32 & 0.04 \\
\hline $\mathrm{MMA}^{\mathrm{c}}$ & -40 & 72 & 68 & 0.56 & 48 & 79 & 0.53 \\
\hline$(R S)$-MBMA & -40 & 24 & 13 & 0.18 & 24 & 89 & $0.50^{\mathrm{d}}$ \\
\hline DMBMA & -40 & 48 & 17 & 0.04 & 24 & 37 & 0.25 \\
\hline TrMA & -40 & 48 & 13 & 0.02 & 24 & 59 & 0.30 \\
\hline
\end{tabular}

a $\mathrm{M}_{1}, 6.8 \mathrm{mmol} ; \mathrm{M}_{2}, 6.8 \mathrm{mmol} ; \mathrm{BuLi}, 0.68 \mathrm{mmol}$; solvent, $8 \mathrm{ml}$.

b Copolymer composition.

c Reference 2.

d A mixture of a homopolymer of ( $R S$ )-MBMA and a copolymer rich in MPhA; this was confirmed by the fractionation of the product of $\mathrm{HBr}$ treatment and from the ${ }^{1} \mathrm{H}-\mathrm{NMR}$ spectra of the methylated fractions.

Table IV. Anionic copolymerization of MPhA $\left(\mathrm{M}_{2}\right)$ and $(S)$-MBMA $\left(\mathrm{M}_{1}\right)$ with BuLi in toluene ${ }^{\mathrm{a}}$

\begin{tabular}{rcccccccc}
\hline $\begin{array}{c}\text { Temp, } \\
{ }^{\circ} \mathrm{C}\end{array}$ & $\begin{array}{c}\text { Time, } \\
\mathbf{h}\end{array}$ & $\begin{array}{c}\text { Yield, } \\
\mathrm{wt} \%\end{array}$ & $\begin{array}{c}\mathrm{m}_{1} / \mathrm{m}_{1}+\mathrm{m}_{2}(\mathrm{~A}), \\
\mathrm{mol} / \mathrm{mol}\end{array}$ & $\begin{array}{c}\mathrm{m}_{2} \mathrm{~m}_{1} \mathrm{~m}_{2}(\mathrm{~B}),{ }^{\mathrm{b}} \\
\mathrm{mol} \%\end{array}$ & $\begin{array}{c}\mathrm{A} \times \mathrm{B}, \\
\mathrm{mol} \%\end{array}$ & $\begin{array}{c}{[\alpha]_{589}^{20},} \\
\mathrm{deg} \mathrm{cm}^{2} / \mathrm{g}\end{array}$ & $\begin{array}{c}{[\alpha]_{\text {caled }},} \\
\mathrm{deg} \mathrm{cm}^{2} / \mathbf{g}\end{array}$ & $\begin{array}{c}{[\Phi]_{\mathrm{Ir}},} \\
\mathrm{deg} \mathrm{cm}^{2} / \mathrm{mol}\end{array}$ \\
\hline-40 & 96 & 55 & 0.21 & 100 & 21 & -1.89 & -2.63 & +1.57 \\
-20 & 24 & 47 & 0.43 & 100 & 43 & -2.84 & -5.18 & +7.18 \\
30 & 24 & 75 & $0.50^{\mathrm{c}}$ & 95 & 48 & -2.67 & -5.97 & +11.62 \\
\hline
\end{tabular}

a $\mathrm{M}_{1}, 6.8 \mathrm{mmol} ; \mathrm{M}_{2}, 6.8 \mathrm{mmol} ; \mathrm{BuLi}, 0.68 \mathrm{mmol}$; toluene, $8 \mathrm{ml}$.

b $\mathrm{m}_{2} \mathrm{~m}_{1} \mathrm{~m}_{2} /\left(\mathrm{m}_{2} \mathrm{~m}_{1} \mathrm{~m}_{2}+\mathrm{m}_{2} \mathrm{~m}_{1} \mathrm{~m}_{1}+\mathrm{m}_{1} \mathrm{~m}_{1} \mathrm{~m}_{2}+\mathrm{m}_{1} \mathrm{~m}_{1} \mathrm{~m}_{1}\right)$.

c Cotacticity, $I: H: S=30: 49: 21$.

and MPhA gave a homopolymer of ( $R S)$-MBMA in addition to a copolymer rich in MPhA. Similar results have been observed in the copolymerization of MPhA and MMA. ${ }^{2}$

The copolymerization of MPhA and ( $S$ )-MBMA was performed in toluene. The results are shown 


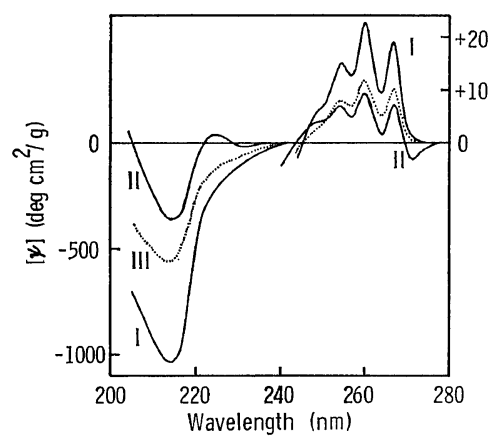

Figure 2. CD spectra of (I) poly[(S)-MBMA] obtained with $\mathrm{BuLi}$ in toluene at $-78^{\circ} \mathrm{C}$ and (II) poly[MPhA-co-(S)-MBMA] obtained with BuLi in toluene at $30^{\circ} \mathrm{C}$. The dotted line $\mathrm{III}$ is the spectrum calculated from the spectrum I and the weight fraction of the $(S)$-MBMA unit in the copolymer.

in Table IV. An alternating copolymer which is atactic was obtained at $30^{\circ} \mathrm{C}$. The copolymers prepared at -20 and $-40^{\circ} \mathrm{C}$ were rich in $\mathrm{MPhA}$. These copolymers showed negative optical rotations. Their absolute values were quite small compared with the calculated values, and the difference between the former and latter values increased as the content of the $\mathrm{m}_{2} \mathrm{~m}_{1} \mathrm{~m}_{2}$ triad increased. In Figure 2 the CD spectrum of the alternating copolymer of MPhA and $(S)$-MBMA is shown together with the spectrum of the $(S)$ MBMA homopolymer. The shapes of the two spectra were somewhat different from each other. The specific ellipticities of the alternating copolymer at 214 and $260 \mathrm{~nm}$ were smaller than those calculated from the content of the $(S)$-MBMA unit.

\section{DISCUSSION}

In the anionic copolymerization of $\mathrm{MPhA}\left(\mathrm{M}_{2}\right)$ and MMA $\left(\mathrm{M}_{1}\right)$, the alternating copolymer was produced at $0^{\circ} \mathrm{C}$ and above. ${ }^{1,2}$ Above the ceiling temperature of $\mathrm{MPhA}$, which is around $0^{\circ} \mathrm{C}$, the MPhA anion at the chain end cannot add this monomer but reacts with MMA. On the other hand, the MMA anion at the chain end may predominantly add MPhA, owing to the higher reactivity of $\mathrm{MPhA} .^{2,3}$ Thus $k_{22} \fallingdotseq 0$ and $k_{12} \gg k_{11}$ in the following propagation reaction, and the alternating copolymerization of $\mathrm{M}_{1}$ and $\mathrm{M}_{2}$ takes place.

$$
\begin{aligned}
& \sim \mathrm{M}_{1}^{-}+\mathrm{M}_{1} \stackrel{k_{11}}{\longrightarrow} \sim \mathrm{M}_{1}^{-} \\
& \sim \mathrm{M}_{1}^{-}+\mathrm{M}_{2} \stackrel{k_{12}}{\longrightarrow} \sim \mathrm{M}_{2}^{-} \\
& \sim \mathrm{M}_{2}^{-}+\mathrm{M}_{1} \stackrel{k_{21}}{\longrightarrow} \sim \mathrm{M}_{1}^{-} \\
& \sim \mathrm{M}_{2}^{-}+\mathrm{M}_{2} \stackrel{k_{22}}{\longrightarrow} \sim \mathrm{M}_{2}^{-}
\end{aligned}
$$

All the methacrylates $\left(\mathrm{M}_{1}\right)$, except for DPEMA, used in this work also formed highly alternating copolymers with $\mathrm{MPhA}\left(\mathrm{M}_{2}\right)$ at 0 and $30^{\circ} \mathrm{C}$ in toluene as well as in THF, as shown in Tables I and II, indicating that these alternating copolymers were produced in the same way as in the MPhA-MMA system described above. However, in the copolymerization of $\mathrm{MPhA}\left(\mathrm{M}_{2}\right)$ and DPEMA $\left(M_{1}\right)$ in toluene, not only was the methacrylate incorporated preferentially but also a high yield of the copolymer was observed. This suggests that the ratio $k_{11} / k_{12}$ was not so small compared with those in the other copolymerizations and that the rate of the copolymerization itself was high. In this case the copolymer composition was in accord with the composition calculated from the polymer yield by assuming that DPEMA was completely consumed and that the remaining unreacted monomer was MPhA alone. Then the monomer reactivity ratio $r_{1}$ can be obtained from the following integral form of copolymerization equation, ${ }^{10}$ since $r_{2}=0$ and $\left[\mathrm{M}_{1}\right]=0$.

$$
\ln \frac{\left[\mathrm{M}_{2}\right]}{\left[\mathrm{M}_{2}\right]_{0}}+\frac{1}{r_{1}-1}\left[\ln \frac{\left[\mathrm{M}_{1}\right]_{0}}{\left[\mathrm{M}_{2}\right]_{0}}\left(r_{1}-1\right)+1\right]=0
$$

where $\left[\mathrm{M}_{1}\right]_{0}$ and $\left[\mathrm{M}_{2}\right]_{0}$ are the initial monomer concentrations and $\left[M_{2}\right]$ is the $M_{2}$ concentration at the complete consumption of $\mathrm{M}_{1}$. The $r_{1}$ values obtained were 0.30 at $0^{\circ} \mathrm{C}$ and 0.37 at $30^{\circ} \mathrm{C}$ in this copolymerization. In such a copolymerization, the addition of $\mathrm{M}_{1}$ monomer to the $\mathrm{M}_{2}$ chain end is the rate determining step, because the reactivities of both the $\mathrm{M}_{1}$ monomer and the $\mathrm{M}_{2}$ anion are relatively low, resulting in low $k_{21}{ }^{10}$ Consequently, the higher $r_{1}$ value and the higher rate of copolymerization observed in the DPEMA-MPhA system is attributed to the higher reactivity of DPEMA against the anions, although the reason for the higher reactivity is not clear at present.

The cotacticity of the alternating copolymer of MMA and MPhA was random, i.e., I: $H: S=$ 
1:2:1. However, in the alternating copolymers of $\mathrm{MPhA}$ with the other methacrylates, the coisotacticity increased with an increase in the size of methacrylate. Some methacrylates, such as DPMMA and TrMA, form highly isotactic polymers in toluene by $\mathrm{BuLi}$, and this seemed to be correlated with the increase in the coisotacticity of the above alternating copolymers. ${ }^{5}$ However, such was not the case, since a similar increase in the coisotacticity was observed in the copolymers prepared in THF, in which most of the methacrylates formed syndiotactic polymers. In the alternating copolymers the bulky substituents may be arranged very tightly and the increase in the steric interaction among them may be favorable for the isotactic addition in the polymerization, where the stereoregularity of the polymer seems to be independent of the polarity of the solvent and, accordingly, of the nature of the counter cation.

In the copolymerization of MMA and MPhA at $-78^{\circ} \mathrm{C}$ in toluene, the polymerization of MPhA occurred preferentially. ${ }^{2}$ The copolymerization of $\mathrm{MPhA}$ and the other methacrylates also gave exclusively the homopolymer of MPhA at $-78^{\circ} \mathrm{C}$. At $-40^{\circ} \mathrm{C}$ the methacrylates were more or less incorporated in the copolymers, but the reactivity of the methacrylates was still low and decreased with increasing bulkiness of their ester groups. In THF the reactivity of the methacrylates increased and gave results similar to those in the copolymerization carried out in toluene at higher temperature, but the lower reactivities of the bulky methacrylates were still observed. The ${ }^{13} \mathrm{C}$ chemical shifts of the $\beta$-carbon in the monomers (Table $\mathrm{V}$ ) indicate that the charge density on the $\beta$-carbon in MPhA is lower

Table V. ${ }^{13} \mathrm{C}^{\beta}$ Chemical shift of MPhA and methacrylates

\begin{tabular}{lrr}
\hline \multicolumn{1}{c}{ Monomer } & $\begin{array}{c}{ }^{13} \mathrm{C}^{\beta}, \\
\mathrm{ppm}\end{array}$ & Reference \\
\hline MPhA & 66.7 & 3 \\
DPMMA & 66.7 & 11 \\
TrMA & 66.8 & 11 \\
BzMA & 67.9 & 11 \\
MBMA & 68.1 & 11 \\
DPEMA & 68.4 & 11 \\
DMBMA & 68.6 & 11 \\
MMA & 68.6 & 3 \\
\hline
\end{tabular}

than those in the methacrylates., ${ }^{3,11}$ The higher reactivity of $\mathrm{MPhA}$ in the copolymerization may be caused not only by the resonance stabilization of its anion due to the existence of a phenyl group at the $\alpha$-position but also by this lower charge density on its $\beta$-carbon. On the other hand, however, the reactivity of the methacrylates in the copolymerization is not in accord with the order of the ${ }^{13} \mathrm{C}$ chemical shifts in Table $\mathrm{V}$, indicating that it is strongly affected by the steric interaction between the comonomers.

In the copolymer of MPhA and (S)-MBMA the alternating sequence of the two monomers contributed to the lowering of the optical activity. If we assume that the optical rotation of the $(S)$ MBMA unit in the copolymer is equal to that in the homopolymer of $(S)$-MBMA, the molar rotation $[\Phi]_{\mathrm{II}}$ of the MPhA unit in the copolymer can be evaluated in the manner used by Carlini, et al., ${ }^{12}$ with the following equation

$$
[\Phi]_{\mathrm{II}}=\frac{[\Phi]_{\mathrm{T}}-N_{\mathrm{I}}[\Phi]_{\mathrm{I}}}{N_{\mathrm{II}}}
$$

where $N_{\mathrm{I}}$ and $N_{\text {II }}$ represent the molar fractions of the $(S)$-MBMA and MPhA units in the copolymer, respectively, $[\Phi]_{T}=M / 100 \times[\alpha]_{589}^{20}$ is the molar rotation of the average unit in the copolymer ( $M$, the molecular weight of the average unit), and $[\Phi]_{\mathrm{I}}$ is the molar rotation based on one $(S)$ MBMA unit. The value $[\Phi]_{\mathrm{I}}$ is tentatively estimated to be $-21.1 \mathrm{deg} \mathrm{cm} / \mathrm{mol}$, the mean value of the molar rotations of isotactic and syndiotactic poly[(S)-MBMA] $(-22.4$ and -19.7 $\operatorname{deg} \mathrm{cm}^{2} / \mathrm{mol}$, respectively). ${ }^{4}$ The results of the calculation are shown in Table IV. The calculated molar rotation of the MPhA unit is positive and increases with increasing content of the $\mathrm{m}_{2} \mathrm{~m}_{1} \mathrm{~m}_{2}$ triad in the copolymer $(\mathrm{A} \times \mathbf{B}$ in Table IV). Therefore, if the MPhA unit contributed to the optical rotation of the copolymer, at least the nearest neighbor MPhA units of the (S)-MBMA unit lowered it with their positive optical rotation, which is opposite in sign to the rotation due to the $(S)$-MBMA unit. Because both the monomers, MPhA and (S)-MBMA, have the same chromophores, i.e., phenyl and carbonyl groups, it is difficult to observe the contribution of MPhA to the CD spectrum of the copolymer. However, in the $\mathrm{CD}$ spectrum the specific ellipticity of each peak was smaller than the corresponding one 
calculated from the weight fraction of the $(S)$ MBMA unit. This may indicate that the electronic transitions of the phenyl and possibly the carbonyl group in the MPhA unit contribute to the chiroptical properties in the opposite direction to the contribution of the $(S)$-MBMA unit.

\section{REFERENCES}

1. H. Yuki, K. Hatada, J. Ohshima, and T. Komatsu, Polym. J., 2, 812 (1971).

2. K. Hatada, J. Ohshima, T. Komatsu, S. Kokan, and H. Yuki, Polymer, 14, 565 (1973).

3. H. Yuki, K. Hatada, T. Niinomi, M. Hashimoto, and J. Ohshima, Polym. J., 2, 629 (1971).

4. H. Yuki, K. Ohta, K. Ono, and S. Murahashi,
J. Polym. Sci., Part A-1, 6, 829 (1968).

5. H. Yuki, K. Hatada, T. Niinomi, and Y. Kikuchi, Polym. J., 1, 36 (1970).

6. H. Yuki, K. Ohta, K. Hatada, and Y. Okamoto, Polym. J., 9, 511 (1977).

7. H. Yuki, Y. Okamoto, Y. Shimada, K. Ohta, and K. Hatada, Polymer, 17, 618 (1976).

8. N. A. Adrova and L. K. Prokhorova, Vysokomol. Soedin., 3, 1509 (1961).

9. K. Ziegler and H. G. Gellert, Ann., 567, 179 (1950).

10. H. Yuki, J. Hotta, Y. Okamoto, and S. Murahashi, Bull. Chem. Soc. Jpn., 40, 2659 (1967).

11. H. Yuki, K. Hatada, K. Ohta, and Y. Okamoto, Appl. Polym. Symp., 26, 39 (1975).

12. C. Carlini, F. Ciardelli, and P. Pino, Makromol. Chem., 119, 244 (1968). 